\title{
Ethylenediamine functionalized-single-walled nanotube (f-SWNT)-assisted in vitro delivery of the oncogene suppressor p53 gene to breast cancer MCF-7 cells
}

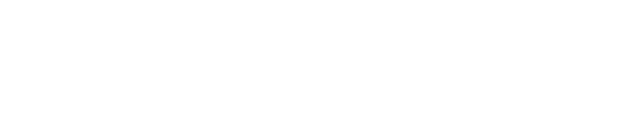

\author{
Alokita Karmakar ${ }^{2}$ \\ Stacie M Bratton' \\ Enkeleda Dervishi ${ }^{2}$ \\ Anindya Ghosh ${ }^{3}$ \\ Meena Mahmood ${ }^{2}$ \\ Yang $X u^{2}$ \\ Lamya Mohammed Saeed ${ }^{2}$ \\ Thikra Mustafa ${ }^{2}$ \\ Dan Casciano² \\ Anna Radominska-Pandya' \\ Alexandru S Biris ${ }^{2}$ \\ 'Biochemistry Department, University \\ of Arkansas for Medical Sciences; \\ ${ }^{2}$ Nanotechnology Center, Applied \\ Science Department; ${ }^{3}$ Department \\ of Chemistry, University of Arkansas, \\ Little Rock, AR, USA
}

\begin{abstract}
A gene delivery concept based on ethylenediamine-functionalized single-walled carbon nanotubes (f-SWCNTs) using the oncogene suppressor p53 gene as a model gene was successfully tested in vitro in MCF-7 breast cancer cells. The f-SWCNTs-p53 complexes were introduced into the cell medium at a concentration of $20 \mu \mathrm{g} \mathrm{mL}-1$ and cells were exposed for 24, 48, and 72 hours. Standard ethidium bromide and acridine orange assays were used to detect apoptotic cells and indicated that a significantly larger percentage of the cells (approx $40 \%$ ) were dead after 72 hours of exposure to f-SWCNTs-p53 as compared to the control cells, which were exposed to only p53 or f-SWCNTs, respectively. To further support the uptake and expression of the genes within the cells, green fluorescent protein-tagged p53, attached to the f-SWCNTs was added to the medium and the complex was observed to be strongly expressed in the cells. Moreover, caspase 3 activity was found to be highly enhanced in cells incubated with the f-SWCNTs-p53 complex, indicating strongly induced apoptosis. This system could be the foundation for novel gene delivery platforms based on the unique structural and morphological properties of multi-functional nanomaterials.
\end{abstract}

Keywords: carbon nanotubes, gene delivery, cancer cells, p53 oncogene suppressor

\section{Introduction}

Nanomaterials, with their unique dimensional and structural properties, have been used in a number of nanomedicine-related applications ranging from cancer targeting, ${ }^{1-3}$ destruction, ${ }^{4-6}$ and visualization ${ }^{7}$ to tissue engineering and regeneration. ${ }^{8,9}$ In particular, carbon nanotubes with their 1D structures were reported to interact strongly with various biological systems ${ }^{10}$ and increase the activity of various drugs used in cancer treatment. ${ }^{11}$ More recently, functionalized single-walled nanotubes (f-SWCNTs) have become one of the most frequently used nanodelivery vehicles and there is great interest in the use of these particles for multiple applications including diagnostics and drug delivery, as well as protein and gene delivery. ${ }^{2,6,10,12-15}$ The generation of f-SWCNT-DNA complexes has been especially beneficial in two ways: 1) the presence of DNA in this complex highly stabilizes the carbon nanoparticle in aqueous suspensions and 2) the DNA molecule is protected from unwanted enzymatic cleavage and nucleic acid binding protein interference when attached to the carbon nanotubes. ${ }^{15-17}$ Another major advantage of using carbon nanotube-based materials as gene vectors is that they do not activate the naive primary B lymphocytes and are thus nontoxic. ${ }^{18}$
Correspondence: Alexandru S Biris Nanotechnology Center, Applied Science Department, 280I S University Ave, Little Rock, AR 72204, USA

Tel +I 50I 55I 9067

$\mathrm{Fax}+$ I 50I 683760 I

Email asbiris@ualr.edu 
One of the genes most frequently delivered to cancer cells is the tumor suppressor protein, p53, which in humans is encoded by the TP53 gene. ${ }^{19-21}$ Protein 53 plays a role in apoptosis, genetic stability, and inhibition of angiogenesis. ${ }^{13}$ Normal cells contain two copies of functional p53 gene, and the protein produced by this gene is activated either to coordinate the DNA repair process or induce cell suicide if DNA damage proves to be irreparable. ${ }^{19,20,22}$ Protein 53 can be activated in response to numerous stressors such as DNA damage, oxidative stress, osmotic shock, ribonucleotide depletion, or deregulated oncogene expression. ${ }^{23}$ When the normal protective function of p53 is lost, the cells lose their potential to control growth, which results in rapid growth and a progression toward malignancy. ${ }^{22}$ In many types of cancers, the loss of p53 activity may also result in resistance to radiotherapy and anticancer drugs. ${ }^{24}$

Protein 53 genes are frequently delivered together with various chemotherapeutic agents, which dramatically increases the efficacy of those drugs. ${ }^{24,25}$ Several in vitro studies clearly suggest that delivery of this tumor suppressor, especially in synergistic combination with cancer drugs, is an efficient mode of cancer treatment. ${ }^{26}$ Although numerous papers have emerged on the use of $\mathrm{p} 53$ as a model gene for testing various methods of gene delivery, such as targeted liposomes ${ }^{27,28}$ or polypeptide delivery vehicles, ${ }^{29}$ to cancer cells, the use of f-SWCNTs has not been reported.

In this work, we have examined the possibility of delivering f-SWNT-DNA complexes containing p53 into MCF-7 breast cancer cells. The major goal of these studies has been to develop protocols for efficient DNA binding and delivery into cancer cells by using the well-characterized p53 gene as a model for cancer cell destruction. These studies have resulted in the successful generation of f-SWCNTs with circular plasmid DNA attached to the outer surface, which, when introduced in vitro to cancer cell cultures, were found to induce apoptosis in a significantly larger percentage of the cells as compared to the nanotubes without plasmid DNA attached to their outside surface. The methods presented here can now be applied as delivery platforms for other genes of interest for various biomedical applications. Using these particles as a foundation, further studies can be developed to generate more advanced particles that can be used for targeting molecules other than genes and/or powerful anticancer drugs.

\section{Materials and methods}

Unless otherwise mentioned, all chemicals were purchased from Sigma-Aldrich (St Louis, MO). The human breast cancer cell line MCF-7 and Dulbecco's Modified Eagle Medium were obtained from American Type Cell Culture (Manassas, VA). The p53 plasmids were purchased from Addgene (Cambridge, MA). The caspase assay kit was purchased from BioVision Inc (Mountain View, CA), and the Gentamucin Reagent Solution was from MP Biomedicals, LLC (Illkirch, France).

\section{Carbon nanotube synthesis}

Single-walled carbon nanotubes were synthesized on a bimetallic $\mathrm{Fe}-\mathrm{Co} / \mathrm{MgO}$ (2.5:2.5:95 wt\%) catalyst system, which was prepared as described previously. ${ }^{30}$ After a thorough overnight drying, the catalyst system was calcinated at $500^{\circ} \mathrm{C}$ for a few hours and about $50 \mathrm{mg}$ of the catalyst was placed on a graphite susceptor, which was inserted into a quartz tube. A radio frequency (RF) generator with a frequency of $350 \mathrm{kHz}$ was used in the synthesis of the carbon nanotubes. Argon (Ar) was first introduced at $150 \mathrm{~mL} /$ minute into the quartz tube positioned inside the RF coil. After 10 minutes, the RF generator was turned on. Once the temperature of the graphite susceptor reached $800^{\circ} \mathrm{C}$, methane was added at $40 \mathrm{~mL} /$ minute for 30 minutes. The carbon source and the RF generator were turned off and the sample was cooled to room temperature under Ar. The produced SWCNTs were mixed into a diluted $\mathrm{HCl}(1: 1)$ solution and the mixture was stirred continuously for 24 hours. The SWCNT mixture was washed with deionized water to a $\mathrm{pH}$ of 7 and dried overnight at $100^{\circ} \mathrm{C}$. The purified SWCNTs were oxidized at $430^{\circ} \mathrm{C}$ for 30 minutes to burn off amorphous carbon and to uncover the remaining catalyst nanoparticles. A second purification of SWCNTs was carried out with a nitric acid treatment to further remove any additional metal impurities. The final product contained SWCNTs functionalized with carboxylic groups with enhanced dispersion properties in various solutions.

\section{Characterization techniques}

A Mettler Toledo (Greifensee, Switzerland) TGA/SDTA 851e was used to carry out thermogravimetric analyses (TGA) with an airflow rate of $150 \mathrm{~mL} / \mathrm{minute}$. Approximately $3 \mathrm{mg}$ of the sample was heated from 25 to $850^{\circ} \mathrm{C}$ at a rate of $5^{\circ} \mathrm{C} /$ minute. Transmission electron microscopy (TEM) images were collected on a field emission JEM-2100F TEM (JEOL Inc, Tokyo, Japan) equipped with a CCD camera and an acceleration voltage of $100 \mathrm{kV}$. For TEM analysis, SWCNTs were homogeneously dispersed in 2-propanol by ultrasonication for 30 minutes. A few drops of the suspension were deposited on the TEM grid and allowed to air-dry 
before analysis. A JEOL 7000F high-resolution scanning electron microscope was utilized to obtain scanning electron microscopy (SEM) images of the purified powdered samples. Before microscopy, the samples were mounted on aluminum pins with double-sided carbon tape.

The optical absorption spectra at UV-Vis-NIR range were recorded using a Shimadzu (Kyoto, Japan) UV-3600 double beam spectrophotometer with three detectors. For the optical measurements, SWCNTs were individually dispersed in an aqueous sodium cholate solution. To obtain a homogeneous solution, the mixture was first sonicated for 1 hour and then centrifuged for 2 hours at $15000 \times g$ using a high speed centrifuge and the supernatant was utilized for optical analysis. Raman spectra of the SWCNTs were collected using a Horiba Jobin Yvon (Kyoto, Japan) Model LabRam HR800 system with a He-Ne laser $(633 \mathrm{~nm})$ as an excitation source. The Raman shifts were calibrated with a silicon wafer at a peak of $521 \mathrm{~cm}^{-1}$.

\section{Synthesis of amine-functionalized SWCNTs (f-SWCNTs)}

In a $100 \mathrm{~mL}$ round-bottomed flask SWCNTs $(50 \mathrm{mg})$, dichloromethane $(50 \mathrm{~mL})$, and $m$-chloroperoxybenzoic acid $(1 \mathrm{~g})$ were mixed and the solution was refluxed for 48 hours. The solution was then filtered to collect the epoxidized SWCNTs and washed with dichloromethane $(2 \times 10 \mathrm{~mL})$ and ethanol $(2 \times 10 \mathrm{~mL})$. The epoxide-functionalized SWCNTs were mixed with lithium chloride $(200 \mathrm{mg}$ ) and freshly distilled ethylenediamine $(20 \mathrm{~mL})$ and the mixture was refluxed for 18 hours under an inert atmosphere. After reflux, the reaction mixture was cooled and filtered to collect the product, which was then washed several times with ethanol $(3 \times 25 \mathrm{~mL})$ to remove any excess ethylenediamine and lithium chloride. The resulting ethylenediamine f-SWCNTs were used for functionalization with the p53 genes.

\section{Functionalization of $\mathrm{f}-\mathrm{SWCNT}$ with $\mathrm{p} 53$ plasmid}

Protein 53 plasmids $\left(20 \mu \mathrm{g} \mathrm{mL}^{-1}\right)$ were added to a suspension of f-SWCNTs in Dulbecco's Modified Eagle Medium (DMEM) medium at a ratio (p53 plasmid:f-SWCNTs) of 1:7.4 (w/w). The solution was mixed thoroughly using a pipette to develop the complex of p53 and f-SWCNTs.

\section{Cell culture}

Human breast cancer cells (MCF-7) were grown in a $75 \mathrm{~cm}^{2}$ culture flask with DMEM, supplemented with $10 \%$ calf serum, $100 \mathrm{U} \mathrm{mL}^{-1}$ penicillin, $100 \mathrm{U} \mathrm{mL}^{-1}$ streptomycin, and $50 \mu \mathrm{g} \mathrm{mL}^{-1}$ gentamicin sulfate and incubated in a $5 \%$ $\mathrm{CO}_{2}$ atmosphere at $37^{\circ} \mathrm{C}$. The cells were subcultured by trypsinization and maintained in aseptic conditions with medium changes every $2-3$ days.

\section{Cell treatment protocol}

The cells were seeded at a density of $25 \times 10^{4}$ cells in each $35 \mathrm{~mm}$ cell culture dish and grown for 72 hours in normal growth medium (as detailed above) until they reached $60 \%-70 \%$ confluence. The medium was then removed and cells were supplied with medium containing $20 \mu \mathrm{g} \mathrm{mL} \mathrm{m}^{-1}$ of F-SWCNTs, $20 \mu \mathrm{g} \mathrm{mL}^{-1}-2.7 \mu \mathrm{g} \mathrm{mL}^{-1}$ F-SWCNTs-p53. A negative control was prepared by incubating the cells only with normal growth medium. The cells were harvested after 24 hours, 48 hours, and 72 hours of incubation for further analysis. All experiments were carried out in triplicate.

\section{Cell assessment with light microscopy}

The cells were plated for microscopy as described above and were washed three times with $10 \times$ phosphate buffered saline (PBS) and examined with an Olympus BX51 light microscope.

\section{Analysis of cell death with ethidium bromide and acridine orange staining}

To determine the degree of cell death, cells were harvested by trypsinization after an appropriate incubation period, were washed twice with $1 \times$ PBS buffer and stained with $17 \mu \mathrm{L}$ of a solution containing $100 \mathrm{mg} \mathrm{mL}^{-1}$ acridine orange and $100 \mathrm{mg} \mathrm{mL}^{-1}$ ethidium bromide in PBS. The harvested cells were placed on a slide and mounted with a cover slide. The stained cells were immediately visualized with UV light using an Olympus fluorescence microscope with a $10 \times$ objective equipped with a digital camera. Images were taken of random fields of view. The percentage of apoptosis was calculated by counting the number of live (green) and apoptotic (red) cells. Acridine orange stained the live cells, thus making them to appear green, whereas the apoptotic cells' fragmented nuclear DNA was stained by ethidium bromide and appeared red when visualized under UV light using specific light filters. Each experiment was run in triplicate and the results expressed as mean \pm standard deviation.

\section{Caspase assay}

Caspase assays were performed to assess the level of apoptosis using the Biovision CaspGLOW Red Active Caspase-3 staining kit. The cells were incubated following the previously mentioned treatment protocol. After incubation, 
both the control and treated cells were trypsinized and the cells were resuspended in $1 \mathrm{~mL}$ of normal growth medium and incubated with $1 \mu \mathrm{L}$ of Red-DEVD-FMK for 1 hour at $37^{\circ} \mathrm{C}$ with $5 \% \mathrm{CO}_{2}$ and then centrifuged for 5 minutes at $3000 \mathrm{rpm}$. The cells were resuspended and washed twice with wash buffer and the final pellet was resuspended in $100 \mu \mathrm{L}$ of the wash buffer. A few drops of the cell suspension were transferred to a microscope slide, which was examined with a light microscope. The brightness level, which indicates the level of caspase activation in the cells, was analyzed for each sample.

\section{Green fluorescent protein expression}

The cells were incubated under the standard conditions using plasmids with green fluorescence protein (GFP) tagged p53. After incubation, both the control and treated cells were harvested, washed twice with $1 \times$ PBS buffer, and visualized under UV light by using an Olympus fluorescence microscope at $10 \times$ objective with an FTIC filter.

\section{Statistical studies}

The data were analyzed by one-way ANOVA test and expressed as mean \pm SD among three separate samples for each condition, the $P$-values of 0.05 or less were considered to indicate significance.

\section{Results and discussion \\ Synthesis and characterization \\ of SWCNTS and f-SWCNTs and p53 \\ complexed f-SWCNTs}

Our work explores the timely topic of nanodelivery of anticancer genes into cancer cells. It is postulated that the internalization of f-SWCNTs-p53 complex and gene expression of $\mathrm{p} 53$ plasmid is a multi-step process (Figure 1). ${ }^{15}$ First, the f-SWCNTs-p53 complex enters into the cytoplasm via endocytosis and then moves to the nucleus. There, the f-SWCNTs-p53 plasmid complex is hypothesized to dissociate, as the amine groups become deprotonated due to an increase in the $\mathrm{pH}$ inside the nucleus. The $\mathrm{p} 53$ plasmid then undergoes transcription followed by transport of the transcripts to the cytoplasm where the p53 RNA is translated. This p53 protein then activates the apoptosis pathways in the cytoplasm.

To produce the detailed experimental data needed to more fully understand each of these steps, fiber-like, singlewalled carbon nanotubes (SWCNT) were synthesized and visualized by TEM (Inset in Figure 2C). Since impurities such as catalyst nanoparticles or carbonaceous by-products strongly affect the electrical, mechanical, and optical properties of the carbon nanotubes, high purity samples with

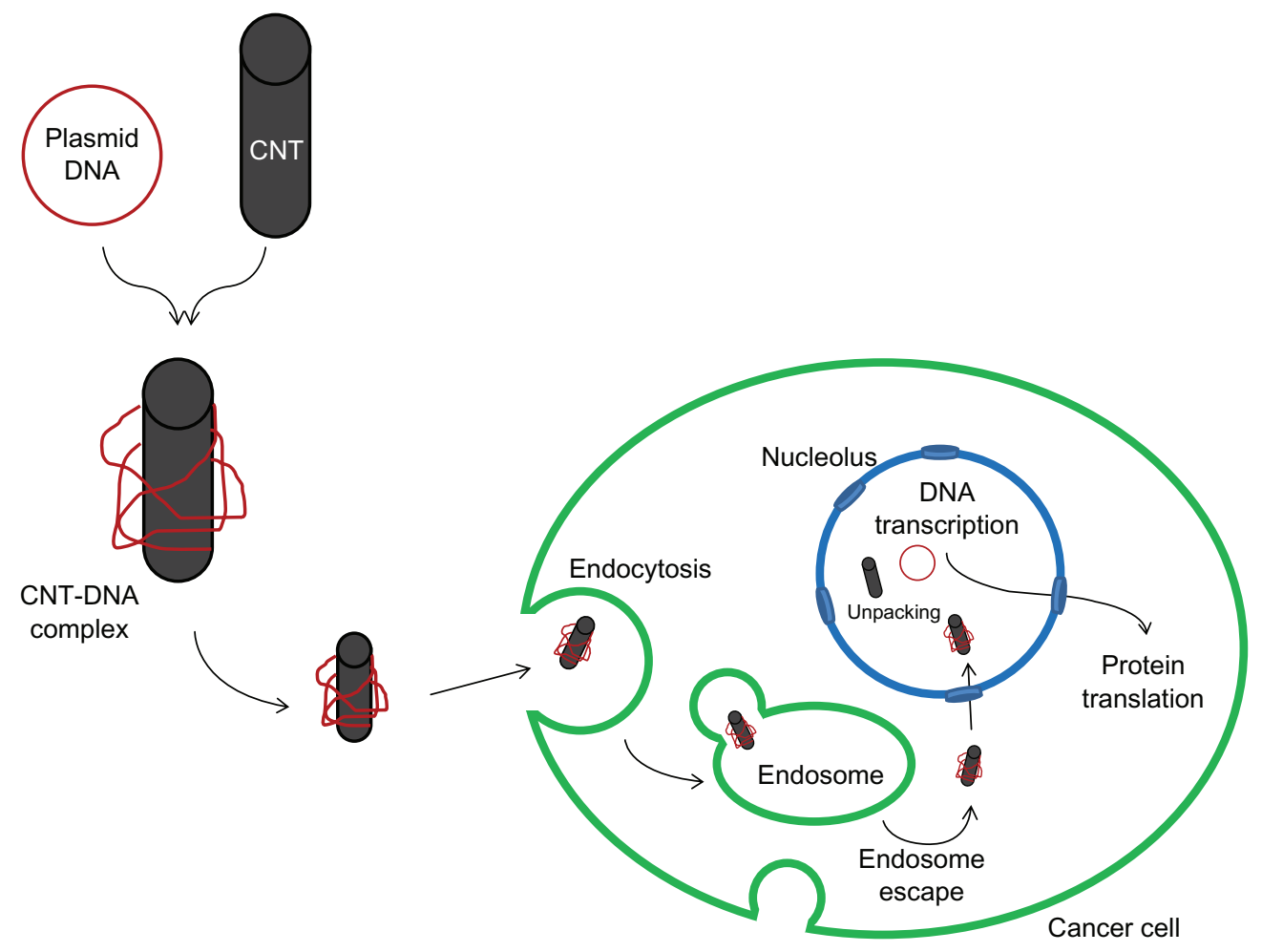

Figure I Schematic representation of f-SWCNT-p53 plasmid complex delivery into the cell and subsequent p53 gene expression. Abbreviation: CNT, carbon nanotubes. 


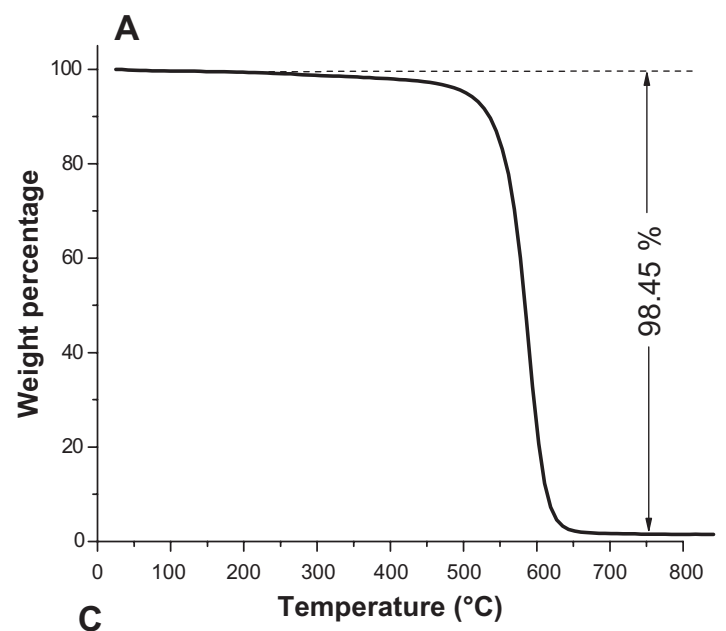

B
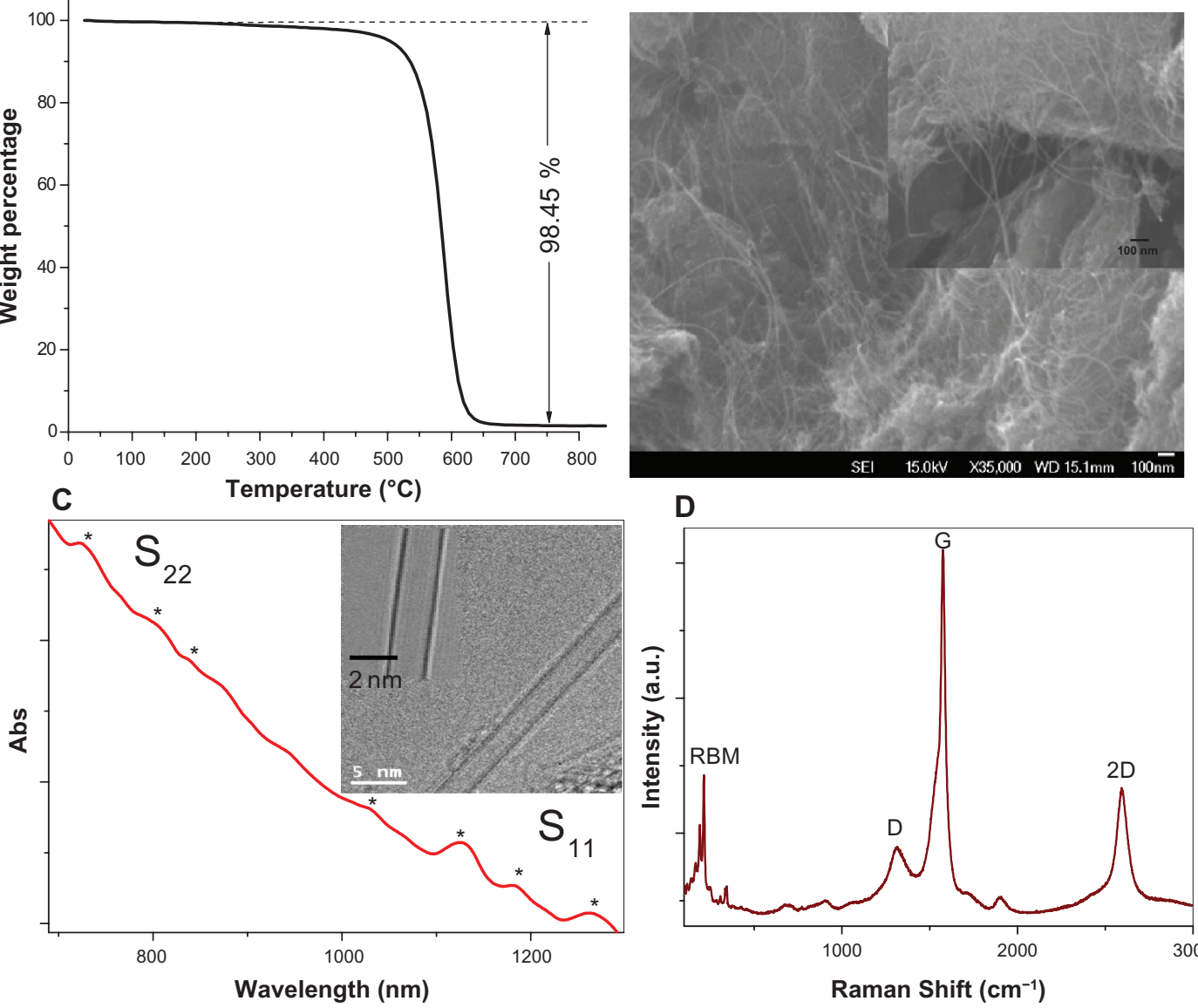

D

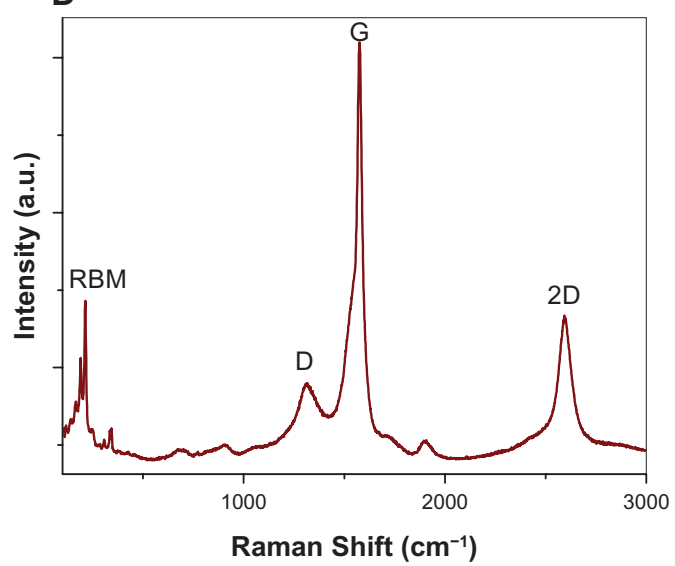

Figure 2 A) TGA analysis of the SWCNTs after purification and removal of amorphous carbon; B) SEM images of the SWCNT bundles synthesized on the bimetallic catalyst system, Inset; C) UV-Vis-NIR spectra of SWCNTs dispersed in aqueous solution. Inset: TEM images of the SWCNTs; D) Raman spectrum of the purified SWCNTs. Abbreviations: SWCNTs, single-walled carbon nanotubes; SEM, scanning electron microscopy; TGA, thermogravimetric analyses.

optimal performance are necessary for various applications. Thermogravimetric analysis is a useful technique for characterizing the purity of carbon nanotubes. ${ }^{31}$ The weight loss profile of the SWCNTs (after purification and removal of amorphous carbon) is shown in Figure 2A and indicates that the purity of the SWCNTs utilized in this work was about $98.45 \%$. Scanning electron microscopy (SEM) was used to analyze the morphology of the CNT products synthesized by RF catalytic chemical vapor deposition. Figure 2B and its inset show the SEM images of CNT bundles with an average length of several microns.

TEM and UV-Vis-NIR spectroscopy were utilized to analyze the diameter distribution of the SWCNTs. The inset in Figure 2C shows the TEM images of the SWCNTs with a diameter of $2 \mathrm{~nm}$. The UV-Vis-NIR spectrum of the isolated SWCNTs (Figure 2C) shows a few absorbance peaks (between 600 to $1300 \mathrm{~nm}$ wavelengths) in the first van Hove optical transitions $\left(\mathrm{S}_{11}\right)$ and the second van Hove transition peaks $\left(\mathrm{S}_{22}\right)$, which correspond to the absorption of the isolated SWCNTs with small diameters. TEM and optical analysis indicated that the SWCNTs utilized in this manuscript have diameters between $0.9 \mathrm{~nm}$ and $2.1 \mathrm{~nm} .{ }^{32}$ Raman spectroscopic analyses were also performed on the purified SWCNTs to further characterize their structural properties. The peaks present in the radial breathing mode (RBM) are often correlated with specific diameters of single-wall carbon nanotubes. ${ }^{33}$ The Raman spectrum shown in Figure 2D indicated the presence of SWCNTs with high crystallinity and with diameters between $0.7-1.7 \mathrm{~nm}$. These values, which were calculated based on the RBM peaks positions present in the Raman spectra of the SWCNTs utilized in this work, are in good agreement with the optical and microscopy findings.

The purified SWCNTs were treated with chloroperbenzoic acid to form epoxidized SWCNTs. This type of functional group was chosen because epoxides are highly reactive, allowing further functionalization with ethylenediamine in the presence of lithium chloride to form amine f-SWCNTs. Due to the presence of free amine groups on the surface, $\mathrm{f}-\mathrm{SWCNT}$ remain protonated when exposed to cell culture medium. As a result, the negatively 
charged plasmid containing p53 DNA is introduced to the positively-charged f-SWCNTs in the medium and the two components form a stable complex due to their strong ionic attractions. A schematic representation of the sequence of the reaction and the steps involved in the production of the f-SWCNT-DNA complexes is shown in Figure 3A. Atomic force microscopy (AFM) images (Figure 3C and 3D) show that the f-SWCNTs are individually dispersed and successfully complexed with the p53 plasmids, which are visible on the sides of the nanotubes. The majority of f-SWCNTs were found to be bound with p53 plasmid when analyzed by AFM. It is also evident from the images that the plasmid DNA is not bound over the entire surface of the f-SWCNTs but rather is localized in specific areas along their length. Most likely, docking of p53 plasmids on the f-SWCNTs occurred with the highest density of protonated amine groups.

\section{Incorporation f-SWCNT-p53 complexes into MCF-7 cells: apoptosis assays and GFP expression}

The uptake and internalization of the f-SWCNT-p53 complexes is shown by optical microscopy in Figure 4A, which indicates that the f-SWCNTs-p53 complexes are found adhered both on the membrane and inside the cells. The agglomeration seen here also supports the hypothesis that the f-SWCNTs-p53 complexes are internalized by the cell, most probably via endocytosis.

In order to follow the events occurring after treatment of the cells with the f-SWCNTs-p53 complexes and to prove that the genes reach the nucleus of the cells, assays were also conducted with f-SWCNTs complexed with a plasmid coding for a p53-GFP fusion protein. Expression of the p53 protein was visualized by tracking the expression of the GFP-tag (Figure 4B-D). ${ }^{35}$ Protein expression, as well as the

\section{A}

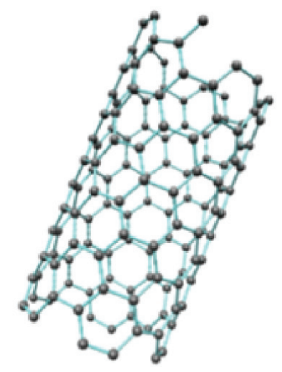

$\underset{\text { ii) Ethylenediamine }}{\longrightarrow}$
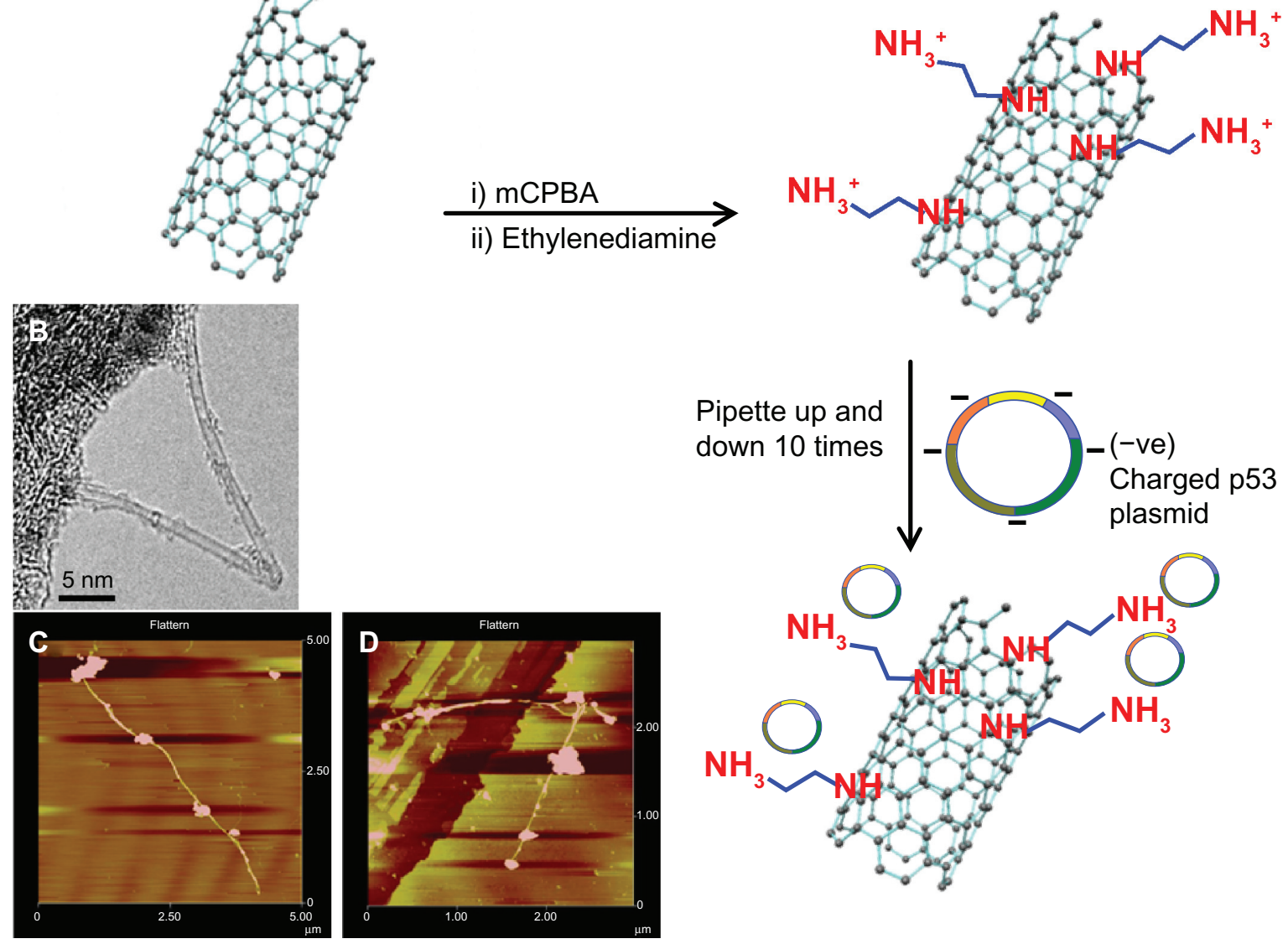

Figure 3 A) Schematic representation of ethylenediamine functionalization of SWCNTs (f-SWCNTs) and formation of f-SWCNTs-p53 complex; B) TEM image of the SWCNTs used in this experiment; $\mathbf{C}$ and D) AFM images of f-SWCNTs-p53 complex formation. The presence of the p53 plasmids on the surface of the nanotubes can be clearly observed. In several cases, multiple $\mathrm{p} 53$ genes were found to be attached to a single nanotube.

Abbreviations: AFM, atomic force microscopy; SWCNTs, single-walled carbon nanotubes; SEM, scanning electron microscopy; TGA, thermogravimetric analyses. 

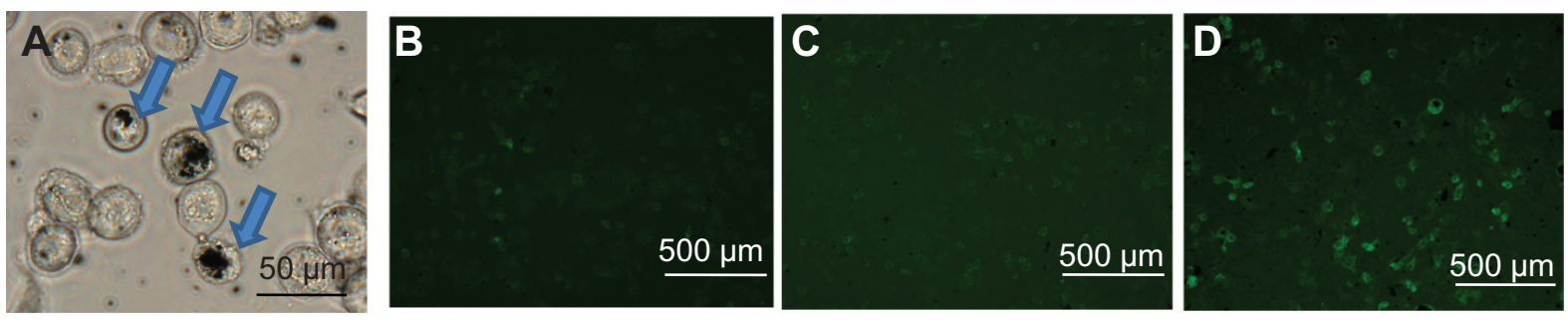

Figure 4 A) Optical image showing uptake of f-SWCNT-p53 complex by MCF-7 cells and agglomeration of f-SWCNT-p53 complex; B-D) Expression of GFP tagged p53 and f-SWCNT complex in MCF-7 cells after 24,48 , and 72 hours of incubation with $20 \mu \mathrm{g} \mathrm{mL}^{-1}$ of f-SWCNTs and $2.7 \mu \mathrm{g} \mathrm{mL}{ }^{-1}$ of GFP tagged $\mathrm{p} 53$ at $37^{\circ} \mathrm{C}$ and $5 \% \mathrm{CO}_{2}$ atmosphere. The arrows indicate the presence of nanotubes inside the cells.

Abbreviations: f-SWCNT, functionalized single-walled carbon nanotubes; GFP, green fluorescent protein.

number of cells expressing GFP, was found to increase with increasing incubation time, with the maximum signal seen after 72 hours.

Figure 5 shows the result of incubation of cells with acridine orange and ethidium bromide to differentiate between viable and dead cells in the control and treatment groups. ${ }^{36}$ Figure 5 shows the effect on MCF-7 cells in cultures with different incubation times (24, 48, and 72 hours; 5A) and treatment with f-SWCNTs (Figure 5B, D-F), p53 plasmid (Figure 5B, G-I) and f-SWCNT-p53 (Figure 5B, J-L) and the control group (Figure 5B, A-C). After 72 hours incubation, the percentage of apoptotic cell death increased dramatically in cells treated with f-SWCNT-p53 and was significantly higher than that seen at other incubation times. The effect of f-SWCNT-p53 in cell death remains very similar to the control groups until 48 hours of incubation, suggesting that cell death was due to initiation of the apoptosis pathway by the expression of p53 and not by any toxic effect of the over-expression of the p53 protein itself.

One important fact is that, for the plasmid to be translocated to the nucleus, it must be separated from the f-SWCNT. This is probably achieved by a change in the $\mathrm{pH}$ in the nucleus compared to the cytoplasmic $\mathrm{pH}$ which facilitates the separation of the p53 plasmids from f-SWCNTs. ${ }^{37}$ It should be noted that the percentage of dead cells in the f-SWCNT treated cells was slightly higher than in the negative control, due to the possible cytotoxic effects induced by the nanomaterials. ${ }^{38}$ The positive control group, where cells were incubated with $2.7 \mu \mathrm{g} \mathrm{mL}^{-1}$ of p53 plasmid under identical experimental conditions, shows results very similar to the negative control group indicating no induction of apoptosis and proving that cells were undergoing natural apoptosis instead of induced apoptosis. This also supported the fact that f-SWCNTs indeed acted as very efficient carriers for the plasmid and incorporated them into the cells. In contrast, the p53 plasmids were unable to penetrate the cells when not attached to the f-SWCNTs, as no induced apoptosis was observed in this group. These data are also in very good agreement with GFP expression, which shows that the 72-hour incubation period provided adequate time for the plasmid to be expressed and activate the apoptotic pathways (Figure 4B-D).

\section{Caspase assay and elucidation of a possible caspase activation pathway}

Caspase assays were conducted to further confirm enhanced apoptosis and provide important information regarding the possible mechanism of apoptosis induced by the wild type p53 plasmid delivered by f-SWCNT. ${ }^{39,40}$ The negative control group showed negligible caspase activity (apoptosis) even after 72 hours (Figure 6, A-C) and the cells treated with f-SWCNT showed similar results (Figure 6, D-F). The enhancement of the caspase signal after 72 hours was not significant when compared to the f-SWCNT-p53 treated group (Figure 6, G-I) although it has a higher signal than the negative control group. This could be explained by possible cytotoxic effects of the f-SWCNT also evident in the ethidium bromide/acridine orange assays.

The caspases are a group of proteins belonging to the cysteine protease family that plays a key role in the apoptosis process. Primarily these proteins remain in an inactivated zymogen form that, upon induction of apoptosis, becomes activated. There are various pathways through which the caspase response occurs during apoptosis. The initiator caspases are the first ones to be activated during apoptosis and are then involved in the activation of effector caspases. These effector caspases lead to the activation and cleavage of other caspases in the entire caspase cascade ultimately, leading to cell death by cleaving other cellular targets.

Based on our data, it is evident that the f-SWCNT-DNA complexes easily enter the cells and are translocated to the nucleus. This is followed by gene transcription and translation as is evident from the visualization of expressed GFP. 
A

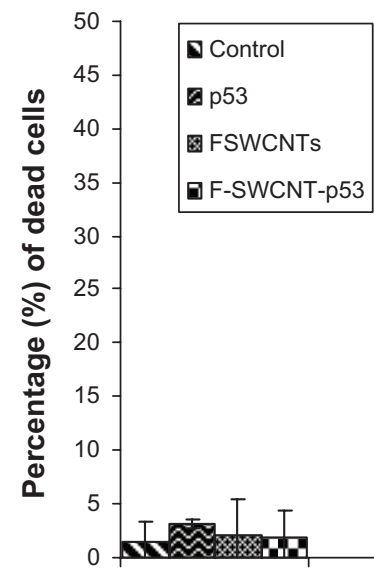

$24 \mathrm{hrs}$

B
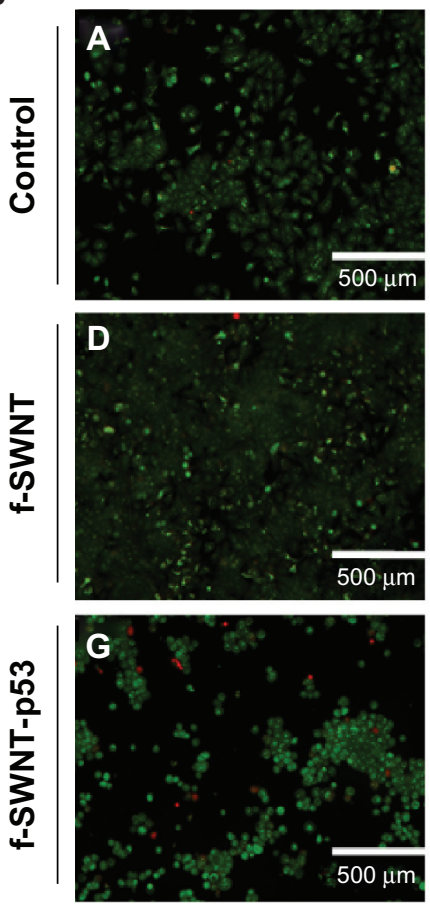
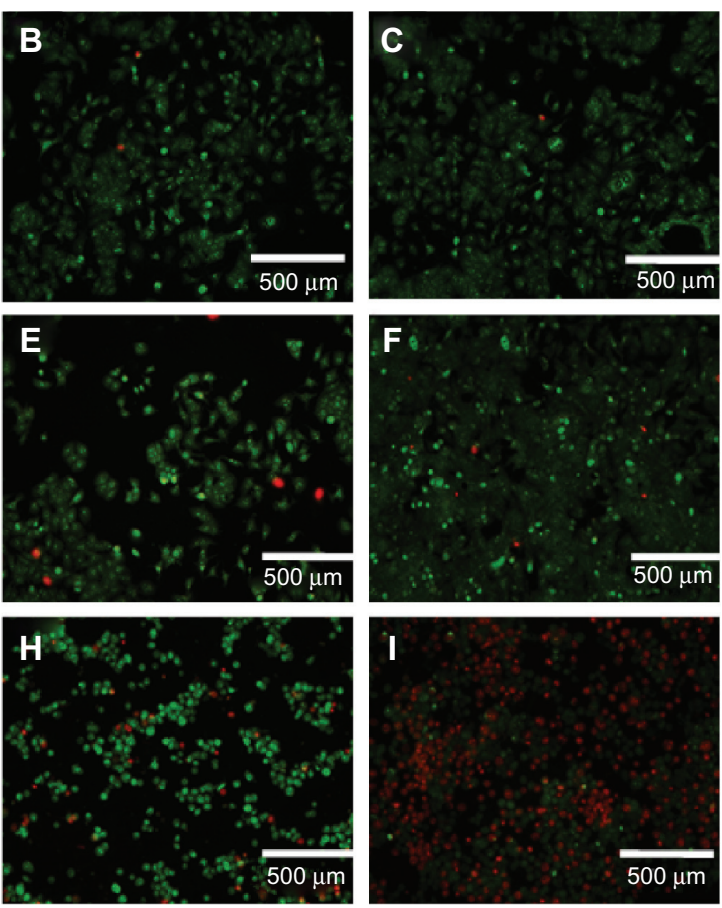

Figure 5 A) Percentage of dead MCF-7 cells in both control and treatment after incubation with normal growth medium and medium containing $20 \mu g \mathrm{~mL} \mathrm{~F}^{-1} \mathrm{f}$-SWCNTs and f-SWCNTs-p 53 plasmid ( $20 \mu \mathrm{g} \mathrm{mL}^{-1}, 2.7 \mu \mathrm{g} / \mathrm{mL}$ respectively) complex for 24,48 , and 72 hours of incubation at $37^{\circ} \mathrm{C}$ temperature and $5 \%$ CO atmosphere; B) Illustration of the effect of F-SWCNTs delivered p53 on induction apoptosis by ethidium bromide/acridine orange assay in MCF-7 cell line, where live cells are green and dead cells appear red when exposed under UV light. A-C) show the control MCF-7 cells (without any treatment); D-F) represent incubation of MCF-7 cells with $20 \mu g / m L$ f-SWCNTs; G-I) MCF-7 cells were incubated with $2.7 \mu \mathrm{g} \mathrm{mL} \mathrm{L}^{-1}$ of $\mathrm{p} 53$ plasmid; J-I) show incubation of MCF-7 cells with $20 \mu \mathrm{gL} \mathrm{mL}^{-1}$ of f-SWCNTs and $2.7 \mu \mathrm{g} \mathrm{mL}$ of GFP tagged p53 plasmid complex at $37^{\circ} \mathrm{C}$ and $5 \% \mathrm{CO}_{2}$ atmosphere.

Abbreviations: f-SWCNT, functionalized single-walled carbon nanotubes; GFP, green fluorescent protein.

We have selected p53 as a model for our studies because it is one of the most significant genes in cancer proliferation. Identified in 1973, p53 was one of the first tumor suppressor genes to be identified ${ }^{41}$ and is the most frequently mutated gene in many common human cancers, with mutations estimated to occur in $50 \%$ of all cancers. The major function of p53 is to repair cell damage or induce cell suicide, inhibiting the proliferation of abnormal cells and preventing neoplastic development. In normal, unstressed cells, the level of $\mathrm{p} 53$ protein is downregulated by the binding of proteins that promote the degradation of p53 via the ubiquitin/ proteasome pathway. The majority of these proteins are also upregulated by p53 itself, which leads to a regulation loop that keeps p53 at very low levels in normal cells. Therefore, the p53 signaling pathway is not active under normal cellular conditions. Activation occurs in response to cellular 

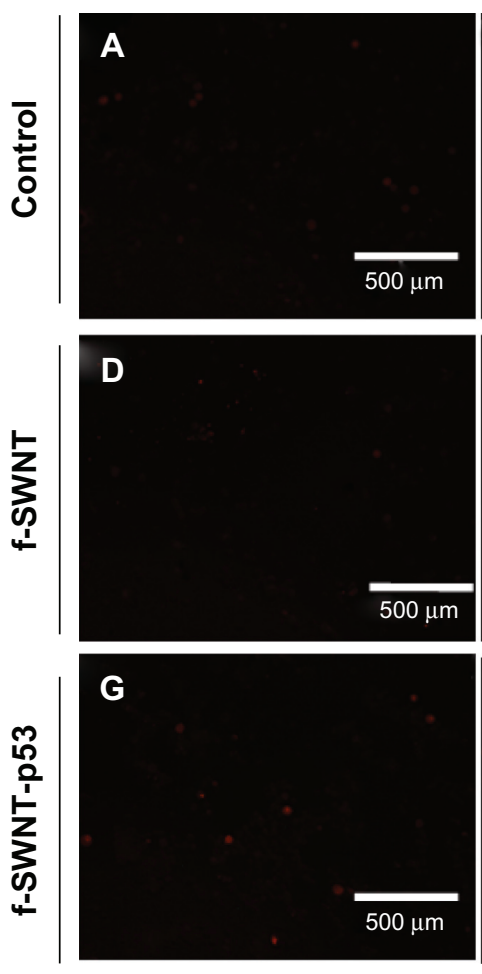

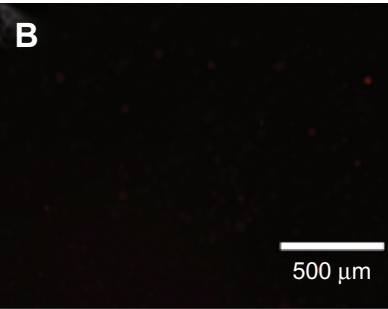

E
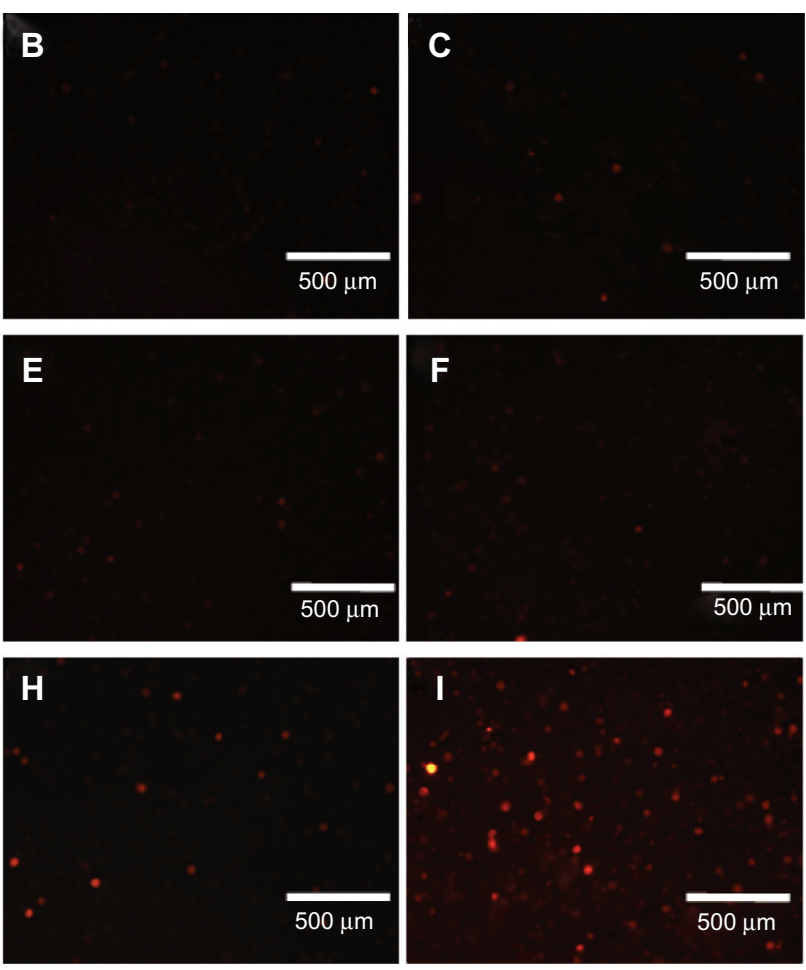

Figure 6 Caspase-3 activity in MCF-7 cells. A-C) the caspase activity in control cells (without any treatment); D-F) caspase activity in MCF-7 cells incubated with $20 \mu \mathrm{mL} \mathrm{L}^{-1}$ f-SWCNTs; G-I) caspase activity in MCF-7 cells incubated with $20 \mu \mathrm{g} \mathrm{mL}$ - of f-SWCNTs and $2.7 \mu \mathrm{g} \mathrm{mL} \mathrm{m}^{-1} \mathrm{p} 53$ plasmid complex for 24,48 , and 72 hours, respectively. The caspase-3 assay was performed following the manufacturer's instructions for the Biovision CaspGLOW Red Active Caspase-3 staining kit; images were taken after exposing the cells under UV light with TRITC filter.

Abbreviation: f-SWCNT, functionalized single-walled carbon nanotubes.

stresses, such as DNA damage, oxidative stress, osmotic shock, ribonucleotide depletion, or deregulation of oncogene expression. ${ }^{23}$ In these stressed cells, negative regulators are inhibited, allowing expressed p53 protein to accumulate, leading to over-translation of p53 RNA, and thus, p53 protein accumulation. Finally, a series of modulators (kinases, acetylases) activate p53 transcriptional activity.

Recently, knowledge of the upstream pathways regulating p53 activity has increased greatly and numerous transcriptional targets for $\mathrm{p} 53$ have been described. These data support an important role for p53 in mammary carcinogenesis. In breast cancer, p53 mutation is associated with more aggressive disease and worse overall survival rates. ${ }^{39,40}$ New data have also emerged that have resulted in the elucidation of other molecular mechanisms, in addition to mutation, by which p53 is disabled in breast cancer and have provided new insights into pathways of neoplasia in this tissue. Genetic and epigenetic changes induced by regulators specific to the activity and transcriptional targets of the p53 gene in breast cancers were recently identified. ${ }^{42}$ A thorough understanding of the molecular pathology corresponding to the structure and expression of constituents of the p53 pathway is expected to have a major impact on the identification, precise diagnosis, and treatment of breast cancer. A number of innovative strategies have been proposed to restore p53 function to tumors. ${ }^{43}$ Our study is among the most recent and we anticipate that ours and other novel therapeutic approaches targeted to the p53 pathway will significantly impact the clinical outcome for patients with breast cancer.

At present, we can only speculate as to the mechanism for the induction apoptotic events after f-SWCNT-p53 treatment. One pathway that could be involved is the upregulation of the BAX protein by expressed p53, with the help of cytochrome-C, which eventually activates the pro-apoptosome complex. The complex activates caspase- 9 that eventually activates caspase-3, leading to the degradation and fragmentation of the chromosomal DNA of the apoptotic cell. ${ }^{44,45}$ However, other mechanisms of caspase activation may contribute to the death of cells and should be taken into consideration. ${ }^{46,47}$ The p53 gene over-expression upregulates the release and activation of one of the $\mathrm{Bcl}-2$ procaspase family proteins. The BAX protein contributes to $\mathrm{p} 53$-dependent tumor suppression and apoptosis in vitro, allocated to the mitochondria, and eventually leads to the activation of cytochrome-C protein through the mitochondrial apoptosis pathway. The presence 
of the procaspase- 9 and the Apaf-1/ATP cofactors will play an important role in apoptosome complex formation and the cleavage of active caspase- 9 into the cytoplasm that has the potential for caspase- 3 activation leading to the degradation and fragmentation of the chromosomal DNA of the apoptotic cell. Furthermore, our results demonstrate the potential of functionalized carbon nanotubes for increasing the induction of apoptosis by the p53 gene that will be implicated for targeted apoptosis-inducing gene therapy.

\section{Conclusions}

In this work, we have demonstrated the ability of f-SWCNT-p53 complexes to penetrate MCF-7 cells and facilitate the delivery of p53 plasmid DNA, resulting in the expression of this protein in these cells. The major purpose of this study was to optimize the methods for binding plasmid DNA to the f-SWCNTs, followed by detailed characterization of these complexes as gene delivery vehicles. It should be emphasized that the technique described in this work is designed to be a tool for the preliminary screening of different genes for their ability to affect cancer cell growth. At this time, the targeted delivery of the genes and the specific type of f-SWCNT used are not as important as their ability to deliver potential anticancer genes to these cells and assess their effects. Experiments using f-SWCNT-DNA complexes for use in selective delivery of specific antibodies to breast cancer cells, as well as f-SWCNTs that are easily biodegradable and nontoxic, are in progress. These studies will allow the techniques to be moved to in vivo models.

\section{Acknowledgments}

Financial support from the Arkansas Science and Technology Authority (ASTA) grant nr 08-CAT-03, the US Army Telemedicine, and Advanced Technology Research Center is highly appreciated. AR-P was supported by the NIHGM075893 grant.

\section{Disclosure}

The authors declare no conflicts of interests in this work.

\section{References}

1. Ou Z, Wu B, Xing D, Zhou F, Wang H, Tang Y. Functional single-walled carbon nanotubes based on an integrin $\alpha v \beta 3$ monoclonal antibody for highly efficient cancer cell targeting. Nanotechnology. 2009;20: 105102.

2. Xiao Y, Gao X, Taratula O, et al. Anti-HER2 IgY antibody-functionalized single-walled carbon nanotubes for detection and selective destruction of breast cancer cells. BMC Cancer. 2009;9:351.

3. Bhirde AA, Patel V, Gavard J, et al. Targeted killing of cancer cells in vivo and in vitro with EGF-directed carbon nanotube-based drug delivery. ACS Nano. 2009;3:307-316.
4. Panchapakesan B, Lu S, Sivakumar K, Teker K, Cesarone G, Wickstrom E. Single-wall carbon nanotube nanobomb agents for killing breast cancer cells. Nano Biotechnology. 2005;1:133-140.

5. Kam NWS, Connell OM, Wisdom AJ, Dai H. Carbon nanotubes as multifunctional biological transporters and near-infrared agents for selective cancer cell destruction. Proc Natl Acad Sci. 2005;102: 11600-11605

6. Dhar S, Liu Z, Thomale J, Dai H, Lippard SJ. Targeted single-wall carbon nanotube-mediated $\mathrm{Pt}(\mathrm{IV})$ prodrug delivery using folate as a homing device. J Am Chem Soc. 2008;130:11467-11476.

7. Malhotra R, Patel V, Vaque JP, Gutkind JS, Rusling JF. Ultrasensitive electrochemical immunosensor for oral cancer biomarker IL-6 using carbon nanotube forest electrodes and multilabel amplification. Anal Chem. 2010;82:3118-3123.

8. Shi X, Sitharaman B, Pham QP, et al. Fabrication of porous ultra-short single-walled carbon nanotube nanocomposite scaffolds for bone tissue engineering. Biomaterials. 2007;28:4078-4090.

9. MacDonald RA, Laurenzi BF, Viswanathan G, Ajayan PM, Stegemann JP. Collagen-carbon nanotube composite materials as scaffolds in tissue engineering. J Biomed Mater Res, Part A. 2005;74A: 489-496.

10. Ladeira MS, Andrade VA, Gomes ERM, et al. Highly efficient siRNA delivery system into human and murine cells using single-wall carbon nanotubes. Nanotechnology. 2010;21:385101.

11. Mahmood M, Karmakar A, Fejleh A, et al. Synergistic enhancement of cancer therapy using a combination of carbon nanotubes and anti-tumor drug. Nanomedicine. 2009;4:883-893.

12. Kam NWS, Dai H. Carbon nanotubes as intracellular protein transporters: generality and biological functionality. $\mathrm{J} \mathrm{Am} \mathrm{Chem} \mathrm{Soc.}$ 2005;127: 6021-6026.

13. Brannon-Peppas L, Blanchette JO. Nanoparticle and targeted systems for cancer therapy. Adv Drug Delivery Rev. 2004;56:1649-1659.

14. Ferrari M. Cancer nanotechnology: opportunities and challenges. Nat Rev Cancer. 2005;5:161-171.

15. Singh R, Pantarotto D, McCarthy D, et al. Binding and condensation of plasmid DNA onto functionalized carbon nanotubes: toward the construction of nanotube-based gene delivery vectors. J Am Chem Soc. 2005; $127: 4388-4396$.

16. Wu Y, Phillips JA, Liu H, Yang R, Tan W. Carbon nanotubes protect DNA strands during cellular delivery. ACS Nano. 2008;2:2023-2028.

17. Bell S, Klein C, Muller L, Hansen S, Buchner J. p53 contains large unstructured regions in its native state. J Mol Biol. 2002;322: 917-927.

18. Cai D, Doughty CA, Potocky TB, et al. Carbon nanotube-mediated delivery of nucleic acids does not result in non-specific activation of B lymphocytes. Nanotechnology. 2007;18:365101.

19. Matlashewski G, Lamb P, Pim D, Peacock J, Crawford L, Benchimol S. Isolation and characterization of a human $\mathrm{p} 53 \mathrm{cDNA}$ clone: expression of the human p53 gene. EMBO J. 1984;3:3257-3262.

20. Isobe M, Emanuel BS, Givol D, Oren M, Croce CM. Localization of gene for human p53 tumor antigen to band $17 \mathrm{p} 13$. Nature. 1986;320: $84-85$.

21. Kern SE, Kinzler KW, Bruskin A, et al. Identification of p53 as a sequence-specific DNA-binding protein. Science. 1991;252: $1708-1711$.

22. Storey A, Thomas M, Kalita A, et al. Role of a p53 polymorphism in the development of human papillomavirus-associated cancer. Nature. 1998;393:229-234

23. Han E-S, Muller FL, Perez VI, et al. The in vivo gene expression signature of oxidative stress. Physiol Genomics. 2008;34:112-126.

24. Li YX, Lin ZB, Tan HR. Wild type p53 increased chemosensitivity of drug-resistant human hepatocellular carcinoma Bel7402/5-FU cells. Acta Pharmacol Sin. 2004;25:76-82.

25. Xu L, Tang W-H, Huang C-C, et al. Systemic p53 gene therapy of cancer with immunolipoplexes targeted by anti-transferrin receptor scFv. Mol Med. 2001;7:723-734. 
26. Gunther M, Wagner E, Ogris M. Specific targets in tumor tissue for the delivery of therapeutic genes. Curr Med Chem Anticancer Agents. 2005;5:157-171.

27. Sapra P, Tyagi P, Allen TM. Ligand-targeted liposomes for cancer treatment. Curr Drug Delivery. 2005;2:369-381.

28. Ledley FD. Nonviral gene therapy: the promise of genes as pharmaceutical products. Hum Gene Ther. 1995;6:1129-1144.

29. Mae M, Langel U. Cell-penetrating peptides as vectors for peptide, protein and oligonucleotide delivery. Curr Opin Pharmacol. 2006;6: 509-514.

30. Dervishi E, Li Z, Xu Y, et al. The influence of Fe-Co/MgO catalyst composition on the growth properties of carbon nanotubes. Part $\mathrm{Sci}$ Technol. 2009;27:222-237.

31. Arepalli S, Nikolaev P, Gorelik O, et al. Protocol for the characterization of single-wall carbon nanotubes material quality. Carbon. 2004; 42:1783.

32. Dervishi E, Li Z, Watanabe F, et al. Thermally controlled synthesis of single-wall carbon nanotubes with selective diameters. J Mater Chem. 2009; 19:3004-3012.

33. Dresselhaus MS, Dresselhaus G, Saito R, Jorio A. Raman spectroscopy of carbon nanotubes. Phys Rep. 2005;409:47-99.

34. Alkhalaf M, Mowafy E-AM. Overexpression of wild-type p53 gene renders MCF-7 breast cancer cells more sensitive to the antiproliferative effect of progesterone. J Endocrinol. 2003;179:55-62.

35. Soboleski MR, Oaks J, Halford WP. Green fluorescent protein is a quantitative reporter of gene expression in individual eukaryotic cells. FASEB J. 2005;19:440-442.

36. Babykutty S, Padikkala J, Sathiadevan PP, et al. Apoptosis induction of centella asiatica on human breast cancer cells. Afr J Trad Cam. 2009;6:9-16.

37. Altan N, Chen Y, Schindler M, Simon SM. Defective acidification in human breast tumor cells and implications for chemotherapy. $J \operatorname{Exp}$ Med. 1998;187:1583-1598.
38. Zhang Y, Ali SF, Dervishi E, et al. Cytotoxicity effects of graphene and single-wall carbon nanotubes in neural phaeochromocytoma-derived PC12 cells. ACS Nano. 2010;4:3181-3186.

39. Aisha AFA, Alrokayan SA, Abu-Salah KM, Darwis Y, Majid Abdul AMS. In vitro cytotoxic and apoptotic properties of the stem bark extract of sandoricum koetjape on breast cancer cell. Int J Can Res. 2009;5:123-129.

40. Benjamin CW, Hiebsch RR, Jones DA. Caspase activation in MCF7 cells responding to etoposide treatment. Mol Pharmacol. 1998; $53: 446-450$

41. DeLeo AB, Jay G, Appella E, Dubois GC, Law LW, Old LJ. Detection of a transformation-related antigen in chemically induced sarcomas and other transformed cells of the mouse. Proc Natl Acad Sci US A. 1979; 76:2420-2424.

42. Gasco M, Shami S, Crook T. The p53 pathway in breast cancer. Breast Cancer Res. 2002;4:70-76.

43. Vogelstein B, Kinzler KW. Achilles' heel of cancer? Nature. 2001;412: 914-921.

44. Schuler M, Green DR. Mechanisms of p53-dependent apoptosis. Biochem Soc Trans. 2001;29:684-688.

45. Gomyo Y, Sasaki J-I, Branch C, Roth JA, Mukhopadhyay T. 5-aza-20-deoxycytidine upregulates caspase-9 expression cooperating with p53-induced apoptosis in human lung cancer cells. Oncogene. 2004;23:6779-6787.

46. Janicke RU, Sprengart ML, Wati MR, Porter AG. Caspase-3 is required for DNA fragmentation and morphological changes associated with apoptosis. J Biol Chem. 1998;273:9357-9360.

47. Steele JA, Prentice GA, Hoffbrand VA, et al. p53-mediated apoptosis of CLL cells: evidence for a transcription-independent mechanism. Blood. 2008;112:3827-3834.
International Journal of Nanomedicine

\section{Publish your work in this journal}

The International Journal of Nanomedicine is an international, peerreviewed journal focusing on the application of nanotechnology in diagnostics, therapeutics, and drug delivery systems throughou the biomedical field. This journal is indexed on PubMed Central,

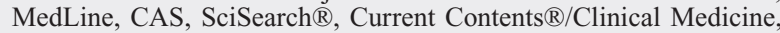

\section{Dovepress}

Journal Citation Reports/Science Edition, EMBase, Scopus and the Elsevier Bibliographic databases. The manuscript management system is completely online and includes a very quick and fair peer-review system, which is all easy to use. Visit http://www.dovepress.com/ testimonials.php to read real quotes from published authors 